\title{
Study on the Current Situation of the Physical Health Promotion Plan Implementation in Jinan's Middle School Students
}

\author{
Qi Shenghua, \\ P.E. School, University of Jinan, \\ Shandong 250022, China
}

\author{
Zheng Kaibiao \\ P.E. School, University of Jinan, \\ Shandong 250022, China
}

Abstract - To know well the current situation of the physical health promotion plan implementation in Jinan's middle school students, 240 students and 30 P.E. teachers in Jinan's Shungeng Middle School, Yuying Middle School, Yuxian Middle School, Qixian Middle School, and Shi Liu Li He Middle School were chosen as the research objects. The cognition of these students and teachers on physical health, how to allocate the spare time, how to look upon the relationship between physical exercise and learning, and the physical exercises involved by the students, the grounds for the exercises, the frequency of taking physical exercises, the forms of physical exercises, and the attitude toward physical exercises were investigated and analyzed using questionnaire survey, literature materials, interview, and mathematical statistics research methods. The results showed that most students were very concerned about their own health and willing to build up their body by taking physical exercises and activities, aiming to promote the life and learning quality and physical health; the physical exercise activities involved by the middle school students were various and chosen by students differently. However, some students did not have enough time to take part in physical exercises because of the effect of the factors such as the network. Therefore, the physical health of some students was worrying. The role of school physical education was not fully played. Some schools gave top priority to the enrollment rate, so that P.E. courses were not offered enough, the contents were boring, the class hours of P.E. courses were occupied by literal arts courses, games were limited, and extracurricular team activities were few. Middle school students' awareness of physical exercises was not enough; the physical education system from schools was not well-improved; the physical educational plan was unreasonable, so that the students' awareness of physical exercises was not cultivated well.

Keywords- Jinan; Middle School Students; Physical Health; Health Promotion

\section{Introduction}

The effective implementation of the student physical health promotion plan in schools is a basis to protect the healthy growth of students and cultivate the useful talents for the society, so it is also a solid foundation for the nation to get prosperous and strong. There are large groups of middle school students in China, and middle school students are the reserve forces of the country to attain development, construction, innovation, and creation. In Jinan, institutions of higher learning and primary and middle schools stand in great numbers, but the levels of educational development are different. The development levels of primary and middle schools in Jinan are greatly different and affected by many negative factors. Thus, the health education for students is ignored, the state's various health promotion measures are not effectively implemented, and the healthy conditions of both teachers and students are poor. By investigation and research and looking for related literature documents, the problems in the current 
implementation of the student physical health promotion plan in Jinan's middle schools were discovered, and the affecting factors and implementation ways of the student physical health promotion plan were explored, making it easy to deeply understand the current implementation of the student physical health promotion plan in Jinan's middle schools. Finally, scientific and reasonable suggestions are raised as references for the ways of implementing the student physical health promotion plan in Jinan's middle schools.

\section{Research objects and methods}

\subsection{Research objects}

In this study, 240 students and 30 P.E. teachers in Jinan's Shungeng Middle School, Yuying Middle School, Yuxian Middle School, Qixian Middle School, and Shi Liu Li He Middle School were chosen as the research objects.

\subsection{Research methods}

\subsubsection{Document literature method}

The document literature works and papers related to this study were searched and consulted by querying the journals, excellent PHD and master theses in CNKI, accessing to the National People's Congress database and electronic reading room, and reading books in library, to provide a theoretical basis for the paper work.

\subsubsection{Questionnaire survey method}

30 P.E. teachers in Jinan's Shungeng Middle School, Yuying Middle School, Yuxian Middle School, Qixian Middle School, and Shi Liu Li He Middle School were surveyed for knowing well every detail of the current implementation of the student physical education promotion plan. In this survey, 30 pieces of questionnaire were randomly distributed, of which 2 pieces of invalid questionnaire were excluded. 28 pieces effective questionnaires were taken back, and the recovery rate was $94 \%$.

\subsubsection{Interview method}

By interviewing the researched students and teachers to know well their attitude toward the implementation of the student physical health promotion plan in Jinan's middle schools and their participation in this promotion, the current situation of the implementation of the student physical health promotion plan was known well. The opinions and suggestions of middle school principals, social science people, P.E. experts and scholars, and leaders of government functional departments about the current situation of the implementation of the student physical health promotion plan in middle schools were collected through interviews and also a variety of restraining factors were exposed.

\section{Research result and analysis}

The current implementation of the student physical health promotion plan in Jinan's middle schools

Analyzed from the overall physical health of middle school students, the current physical health conditions were good, but the overall physical health level urgently needed an increase and there were some problems that should never be ignored.

\subsection{Attitude toward the implementation of the student physical health promotion plan in Jinan's middle schools}

The survey found that 180 research objects had a good positive attitude toward physical exercise and health, accounting for $90 \%$ of the total; 20 research objects had a negative attitude, accounting for $10 \%$. The result showed that most research objects were very concerned about their physical health and willing to build up the body through physical exercises and activities, aiming to promote the learning and life quality and the physical health, as shown in table 1 . 
Table 1: Attitude toward the implementation of the student physical health promotion plan in Jinan's middle

\begin{tabular}{ccc}
\multicolumn{3}{c}{ schools } \\
\hline Motivation & Number of research objects & Percent $(\%)$ \\
\hline To build up body & 146 & 73 \\
To promote the learning and life quality & 128 & 64 \\
Personal interests and hobbies & 112 & 56 \\
To make friends & 103 & 51.5 \\
To prevent illness & 96 & 48 \\
To prove self-worth & 56 & 28 \\
Need to recover from illness & 23 & 11.5 \\
To blindly follow & 15 & 5.5 \\
\hline
\end{tabular}

To have good physical quality is demanded by every student in society, but many middle school students have not been aware of tailoring an exercise plan, so that they often took part in physical exercises simply for some reasons. To conclude, there is plenty of room for improvement.

\subsection{Implemented contents of the student physical health promotion plan in Jinan's middle schools}

Seen from table 2, the physical exercises Jinan's middle school students took part in were relatively rich, and most students made multiple different choices because of diversified activity forms. In terms of chosen contents, $87.5 \%$ of middle school students chose running, $72.5 \%$ chose basketball, $64 \%$ chose table tennis, and $43 \%$ chose aerobics if spare time was enough, $37.5 \%$ chose rope skipping, $26.5 \%$ chose football, $19 \%$ chose volleyball, and $13 \%$ chose other sports.

Table 2: Implemented contents of the student physical health promotion plan in Jinan's middle schools

\begin{tabular}{cccc}
\hline Sport & Number of research objects & Percent $(\%)$ & Rank \\
\hline Running & 175 & 87.5 & 1 \\
basketball & 145 & 72.5 & 2 \\
table tennis & 128 & 64 & 3 \\
aerobics & 86 & 43 & 4 \\
Rope skipping & 75 & 37.5 & 5 \\
Football & 53 & 26.5 & 6 \\
volleyball & 38 & 19 & 7 \\
Other & 26 & 13 & 8 \\
\hline
\end{tabular}

\subsection{Implementation time and frequency of the student physical health promotion plan in Jinan's middle schools}

Seen from table 3, 99\% of middle school students would attend school's P.E. courses on the premise of no special circumstances. In this period, most students would get physical training. $78 \%$ used spare time to take part in physical exercises, but the activity forms were simple and the exercise intensity was low, so that they could not get 
endurance training and strength training for a long time.

Table 3: The implementation time of the student physical health promotion plan in Jinan's middle schools

\begin{tabular}{cccc}
\hline The time of exercise & $\begin{array}{c}\text { Number of research } \\
\text { objects }\end{array}$ & Percent (\%) & Rank \\
\hline P.E. courses & 198 & 99 & 1 \\
Spare time & 156 & 78 & 2 \\
Weekend & 97 & 48.5 & 3 \\
After school & 63 & 31.5 & 4 \\
To blindly follow & 45 & 22.5 & 5 \\
\hline
\end{tabular}

Seen from table $4,70 \%$ of middle school students spent about less than one hour on physical exercises in the spare time every day; only
$7.5 \%$ spent more than two hours. One hour for exercises was only rarely part of their spare time.

Table 4: The implementation frequency of the student physical health promotion plan in Jinan's middle schools

\begin{tabular}{cccc}
\hline $\begin{array}{c}\text { Duration of physical exercises } \\
\text { every day }\end{array}$ & Male students (\%) & $\begin{array}{c}\text { Female students } \\
(\%)\end{array}$ & Percent (\%) \\
\hline Within 30mins & 35 & 15 & 25 \\
30mins-1h & 46 & 44 & 45 \\
$1-2 \mathrm{~h}$ & 15 & 30 & 22 \\
$>$ 2h & 3 & 12 & 7.5 \\
\hline
\end{tabular}

\section{Problems in the implementation of the student physical health promotion plan in Jinan's middle schools}

First, the role of school physical education was not fully played. Physical exercise is a key factor to the body's growth and development. School physical education is an important part of popular sports, but also a foundation of the national sports.

Second, the middle school students' awareness of physical exercises was not enough. The awareness of physical exercises is objective existence in the mind of people to reflect the people's sports feeling, thinking and judgment, and it is the people's total understanding of physical exercises.

Third, the spare time for physical exercises is limited. Heavy school work, not enough after-class life, and students' weak awareness of physical exercises made the after-school free time dominated by students limited. Moreover, insufficient sleep, absent interest in physical exercises, and less understanding of exercise ways made the time arranged by students more limited for physical exercises. Along with the rise of the Internet, computers and video games and a lot of homework, students sat for a longer time so that they did not relax and regulate their body. This was very bad for the physical health of students. The limited extracurricular time and the undesirable life habits gave rise to the loss of the students' physical health.

\section{Conclusion and suggestions}

\subsection{Conclusion}

First, most students in Jinan's middle schools were very concerned about their own physical health and willing to build up their body through physical exercises and activities, aiming to promote the learning and life quality and the physical health. 
Second, the physical exercises Jinan's middle school students took part in were rich and most students had multiple choices - activity forms were diversified so that the choices were different. Third, Jinan's middle school students' awareness of physical exercises was weak and good exercise habit and plan were absent.

Fourth, the extracurricular life of Jinan's middle school students was not enough diversified, and the students' awareness of physical exercises was weak, so that the spare time for time to dominate was rather limited, and school team work was rare.

\subsection{Suggestions}

First, in the school's physical educational construction, the "health first" guiding ideology is necessarily fully implemented; the middle school students are encouraged to actively take part in physical exercises, cultivate good exercise habit and lifelong sports awareness and make a good exercise plan.

Second, in the school's physical education, students are necessarily promoted to know well the importance of physical exercises to physical health, take part in physical exercises as much as possible, intentionally increase the frequency, duration and intensity of physical exercises, and set up a correct outlook on physical education.

Third, the survey found that the middle school students' learning tasks are heavy, and tight time is one of the biggest factors affecting the after-school activities of students.

\section{Acknowledgement}

This paper aided financially by the National Social Science Fund Project, "Study on the
Co-construction of Primary and Middle School Students Health Promotion Model by Families and Schools Based on the Standards Of Course Sports and Health" (No.13BTY037).

\section{References}

[1] Lei Feng. Investigation and Research on the Current Situation of the Implementation of "sports and health standards" in Jinan's Junior High Schools [D]. Shandong Normal University, 2008, 9-12.

[2] Gaohua Wang. Rationally Thinking the Evolution and Development of Student Physique Healthy Standards [J]. Journal of Capital Institute of Physical Education, 2004 (02): 1-4.

[3] Shu-fang Mao, Jianhua Wu. How to Cultivate Students' Interest in Sports in the Physical Educational Process of Schools [J]. Journal of Corps Education College, 2007 (6): 76-78.

[4] Weiwei Ding. Study on the Current Implementation of Measures to Promote the Health Standards in the Primary and Middle Schools in Wuhan and the Countermeasures [D]. Central China normal university, 2008: 13-19.

[5] Liu Shuang'en, Hui Yan, Heling Zhang. Study on the Influence of "Sunshine Sports" on Taiyuan's Junior High School Students' Physical Quality [J]. Fight BBS (Sports), 2011, 23 (6): 32-34.

[6] Qian Wang. Study on the Current Teaching Situation of course "sports and health" in Some Junior High Schools of Qinhuangdao [D]. Shanghai Sports Institute, 2011: 5-10. 